\title{
Hacia la morfo-logía
}

\section{Towards Morpho-logy}

\author{
Federico Vercellone \\ escrituraeimagen@filos.ucm.es
}

Recibido: 02/06/2011

Aceptado: 20/06/2011

\section{Resumen}

La "muerte de Dios" sacó a la luz un nuevo saber "prediscursivo" que propicia la aparición de nuevas estructuras simbólicas y un giro "ecológico" de la teoría de la imagen. Gracias a éste, la Anschauung o intuición, que había quedado relegada a la condición de residuo objetivado de un saber mucho más completo, el saber de la imagen, vuelve a adquirir su dimensión originaria (y final), abriendo el camino a una nueva racionalidad. A través del reconocimiento de la profundidad de la Anschauung emerge una lógica de la estructura de la imagen que parece colindar con una lógica de la forma. Forma entendida como una estructura de la copertenencia de yo y naturaleza, de sujeto y objeto. Podríamos definirla como una morfo-lógi$c a$, una lógica que articula la intuición, la Anschauung, y que la expresa como estructura compleja en la imagen.

Palabras clave: intuición, imagen, morfología, sujeto, objeto.

\section{Abstract}

The "death of God" brought to light a new "prediscursive" knowledge that favours both the emergence of new symbolic structures and an "ecological" turn in the theory of image. Thanks to this knowledge, the Anschauung or intuition, which had been relegated to the status of an objectified residue of a much more complete knowledge - that of the image--, regains its original (and final) dimension paving the way for a new rationality. Through the acknowledgement of the depth of the Anschauung, it appears a logic of the structure of the image that seems to adjoin with a logic of form. That form is understood as a structure of co-belonging of self 
and nature, subject and object. It could also be described as a morpho-logic, a logic that articulates intuition, the Anschauung, and that expresses it as a complex structure in the image.

Keywords: Intuition, image, morphology, subject, object.

\section{Sumario}

1. Premisas

2. El "giro icónico"

3. Morfo-lógica. Más allá de la estetización de la imagen

4. Apariciones

\section{Premisas}

Bien sabemos que la "muerte de Dios" es un evento absolutamente religioso. En el aforismo 125 de La gaya ciencia y en la sucesiva reflexión teológica, la naturaleza religiosa de este evento resuena con su trágica potencia. Que es trágica en la medida que es religiosa, y que es religiosa y trágica en la medida que se produce como un evento sacrificial. Por lo demás, afirma "el hombre loco":

Lo más sagrado y lo más poderoso que el mundo poseía hasta hoy se ha desangrado bajo nuestros cuchillos: ¿quién nos limpiará de esta sangre? ¿Con qué agua podremos lavarnos? ¿Qué ritos expiatorios, qué juegos sagrados podremos inventar? ¿No es demasiado grande para nosotros la grandeza de esta acción? ${ }^{1}$

Pero no estamos únicamente ante un evento trágico sino también sobre un terreno tan fértil que produce continuos renacimientos de Aquél a quien se había dado muerte. Tal como he intentado mostrar en otra parte ${ }^{2}$, esto vale no sólo para la "muerte de Dios" sino también para las otras muertes u homicidios "simbólicos" que recorren el siglo XIX. En efecto, resulta suficientemente conocido que el siglo XIX es el teatro de numerosas muertes de entes, de sustancias, de entidades universales que difícilmente podrían ir al encuentro de un deceso biológico. Y que, sin embargo, van al encuentro de suntuosas muertes simbólicas de extraordinaria y sorprendente eficacia que las hacen susceptibles de numerosos renacimientos. Por ejemplo, la enseñanza hegeliana que se nos ha confiado en las Lecciones de estéti-

\footnotetext{
1 Nietzsche, F., Opere complete, a cargo de G. Colli e Mazzino Montinari, vol. 5/2: Idili di MessinaLa gaia scienza - Frammenti postumi (1881-82), Milano, Adelphi, 1965.
} 
$c a$ concerniente al "fin del arte" se ha transformado a fin de cuentas en el diagnóstico de la "muerte del arte" sobre el que, desde Croce a Bosanquet, se ha desarrollado un amplísimo debate que llega hasta nosotros. Después del arte que, muriendo, se obstina en vivir hasta hoy gozando de óptima salud, muere también el hombre en el siglo XIX: lo anuncian Stirner y Dostoievski ${ }^{3}$. La muerte del hombre será también, por su parte, la premisa para el renacimiento de amores renovados por la especie desafortunada, para el renacimiento de esos humanismos, de esa pasión por la idea de humanidad que se difunde en la segundad mitad del siglo XIX y en la primera del XX. La "muerte de Dios" resulta, en este ámbito, la última en llegar, como si pretendiese sancionar el cumplimiento de pomposas catástrofes. Se trata también en este caso de una muerte que no defrauda a los herederos. Y resulta casi inútil lamentar lo que sucede ante los ojos de todos: ¿cuántos siglos hace que no se combatía como se hace hoy, y con tanta saña, en nombre de Dios?

Casi resulta inútil también recordar aquello que ha sido recordado tan a menudo, a saber, que con la "muerte de Dios" lo que muere no es el Dios viviente sino el Ente supremo, el "Dios de los filósofos" si retomamos el famosísimo título de la obra de Wilhelm Weischedel ${ }^{4}$. En este ámbito no nos interesa la cuestión desde el punto de vista teológico sino más bien desde el propiamente conceptual. Desde este punto de vista, la muerte de de Dios comporta entre otras cosas -ésta es la tesis que aquí querría sostener- respecto del orden rígido dictado por la jerarquía conceptual dominada por el Ente supremo, dentro del ámbito que Heidegger define como ontoteología, el salir a la luz de un nuevo saber que podría ser definido como "prediscursivo" y que pertenece a una esfera más amplia, cambiante y a veces confusa. La tesis que, en otros términos, se quiere aquí proponer es que la muerte de Dios, al no satisfacer las condiciones requeridas por la noción de Ente supremo en cuanto auténtica realización del orden conceptual y discursivo, produce al mismo tiempo el desbordamiento y el reconocimiento de nuevas estructuras simbólicas, de aspecto exuberante e inquietante a la vez, que se anuncian desde los orígenes pre-nietzscheanos de este anuncio, quizás desde la mirada atónita que dirigen los resucitados al vacío ojo de Dios en los Discurso de Cristo muerto de Jean Paul5.

De hecho, en lo prediscursivo se mezclan los sentimientos y las intuiciones, las imágenes y las precogniciones. Podríamos decir que aquí emerge por encima de todo esa esfera que -para decirlo en términos absolutamente genéricos y vagos-en

\footnotetext{
2 Cfr. Vercellone, F., Der symbolische Mord. Der Mord der Kunst, des Menschen un Gottes zwischen Hegel und Nietzsche, en Der "Mord". Darstellung und Deutung in den Wissenschaften und Künsten, hrsg. Von D.v.Engelhardt und Oehmichen, M., Lübeck, Schmidt-Römhild, 2007, pp. 163-171.

3 Por lo que se refiere a la identificación global de los temas mayores que conciernen al nihilismo y que aquí me limito a señalar, ruego se me permita hacer referencia a mi Introduzione a Il nichilismo, Roma-Bari, Laterza, 1992.

4 Cfr. Weischedel, W., Il Dio dei filosofi, 3 vols., Genova, Il Melangolo, 1966 y ss.

5 Jean Paul, Il discorso del Cristo morto, Milano, SE, 1997.
} 
el círculo de la gnoseología y en el pensamiento moderno había sido relegada al ámbito de la pasividad.

Limitémonos -como se va a hacer en este texto- a un breve ejemplo refiriéndonos a la imagen en clave metonímica, con la esperanza de que, gracias a este ejemplo precisamente, se abra una rendija a la totalidad de la cuestión. En tanto en cuanto la imagen es el resultado de una objetivación realizada por el sujeto, la intuición que la origina se puede reconducir a mecanismos racionales, deviene un dato de la conciencia, una percepción y objeto por tanto del conocimiento conceptual. Este es el primer aspecto de su ser "pasiva". Cuando se perfila, por otra parte, desde su autonomía respecto del sujeto, se contempla la imagen como algo diferente de la razón y queda situada en consecuencia en una dimensión distinta de la pasividad, en lo residual, en aquello que ya no es activo porque ha perdido, al presente, sus antiguos derechos. Tal como el padre reprocha a Heinrich en el Heinrich von Ofterdingen de Novalis, éste ya no es el tiempo en que el sueño puede desempeñar un papel profético:

En la época en que vivimos ya no es posible establecer un contacto directo con el cielo 6 .

Aquí se oculta la posibilidad, ampliamente reconocida por los románticos y por Schelling, de un saber de la naturaleza en el sentido objetivo y subjetivo del término. Y se trata de un saber que se relaciona con la naturaleza en su modalidad expresiva. Para definir en los términos más generales el origen de este saber, se puede decir que mana de los pliegues de la Anschaunng, de la intuición, de aquello que ha sido definido como dato sensible contrariando así, al menos en parte y mediante esta transformación, su derivación de la experiencia de lo visible (que se deja percibir más sensiblemente en el étimo alemán). Precisamente en cuanto dato, tal cosa es el correlato pasivo de un elemento activo o al menos performativo como el concepto. Todo cuanto se querría ahora sostener-teniendo en cuenta también los resultados de ese giro en dirección a la imagen en la cultura contemporánea que ha sido definido como iconic turn-es que la intuición es el residuo objetivado de un saber mucho más completo, el saber de la imagen. En efecto, el saber de la imagen es un saber que se querría concebir como auto-exposición de la naturaleza. Dado que se propone al conocimiento como fenómeno -según había observado certeramente Goethe- la naturaleza se ofrece a la contemplación, o sea, en imagen. Ella tiende, pues, a producir en la superficie, recurriendo a lo visible, su propia estructura profunda e inaccesible en principio 7 .

\footnotetext{
${ }^{6}$ Novalis, Heinrich von Ofterdingen, en Schriften I, Das Dichterische, hrsg. Von P. Kluchohn und R. Samuel, 3., nach d.Hs.erg., erw.U.verb. Aufl., Stuttgart, Kolnhammer, 1977, p. 198.

7 Cfr. infra, caps. 2 y 3 , en particular la p. 37.
} 


\section{El "giro icónico"}

Tal como se aludía más arriba, nos encontramos con toda probabilidad muy cerca de otro gran cambio de dirección del saber que responde a aquel otro que JeanFrançois Lyotard había definido como posmoderno hace ahora treinta años ${ }^{8}$. Como resulta incluso demasiado conocido, Lyotard sostenía que estábamos ante una pérdida de credibilidad de los grandes relatos y ante el entrelazarse de discursos que podrían ser definidos como de "universalidad limitada", es decir, que ya no son capaces de sintetizar el conjunto de una cultura y, eventualmente, ni siquiera de expresar sus esperanzas, de proporcionarle un horizonte axiológico. Se asistía, en otros términos, a una fragmentación del discurso en sus pretensiones de universalidad. Todo ello había producido, Italia incluida (recojo el título cautivador de un libro de esos años), la idea de una "crisis de la razón"9 que coincidía con aquella que al modo de Hegel se podría definir como su Zerrissenheit, su desgarramiento. Este efecto de desgarro se presentaba además como ambivalente: por un lado podía provocar la nostalgia de todo aquello que se había perdido, por otro parecía proponer la idea o el ideal de una posible emancipación de la propia razón de sus vínculos con la razón clásica. Se trataba, en otros términos, de la idea de una razón que libera las diferencias y no las vincula bajo su yugo. Un proyecto que fue llamado "pensamiento débil", representado en particular por Gianni Vattimo que, al menos desde este punto de vista, representaba también un modelo de pensamiento neoilustrado 10 .

Para expresarlo en términos seguramente demasiado esquemáticos, los términos (¡a veces dramáticamente disputados!) de la alternativa propuesta ya no parecen ser los nuestros. El giro ante el cual hoy nos encontramos es profundamente diverso de aquel que Lyotard describió hace treinta años. Sin embargo, quizás sea un hijo, anticipado en parte por el propio Lyotard. En efecto, como éste percibía en Le Différend, el conflicto de las interpretaciones había dejado al descubierto fallas que se abrían sobre lo no-discursivo, en dirección a una dimensión a-racional en cuanto trágicamente indecidible que ha ido adquiriendo un alcance cada vez más amplio en todos los planos de la cultura11.

Se tiene la impresión de haber descubierto una zona de pertenencia originaria de los lenguajes y de las culturas, una zona que podríamos definir como de "alta connotación antropológica", definida por una semántica densa pero no conceptual. Ella deriva de una reactivación del saber de la Anschauung, de ese saber de la intuición que se desarrolla cuando esta última vuelve a adquirir su dimensión originaria

\footnotetext{
8 Lyotard, J-F., La condition postmoderne, Paris, Minuit, 1979.

9 Cfr. La crisi della ragione, a cura di A. G. Gargani, Torino, Einaudi, 1979.

10 La temporada se abrió con la famosa obra El pensamiento débil, a cargo de G. Vattimo y P. A.

Rovatti, Milano, Feltrinelli, 1983.

11 Lyotard, J-F., Le Différend, Paris, Minuit, 1983.
} 
(y final) que es la imagen. Ella deriva de una inversión de la dimensión objetivante ínsita en la intuición de... y se propone a la vez como pertenencia a, como "cruce de las miradas"12. La lógica de la imagen, en su derivación del ser natural que se entreabre con la visión, se propone desde esta perspectiva como una lógica de las formas vivientes.

Se abre aquí una cuestión de primerísimo nivel no exenta en modo alguno de dificultades. Nos las vemos en efecto ante un giro que definiría como "ecológico" de la teoría de la imagen. Naturalmente, no es posible sustraerse en este caso a una referencia a la fenomenología y al pensamiento de Merleau-Ponty. Con todo, la cuestión no se relaciona exclusivamente con la corporeidad como reino común en que se fraguan sujeto y mundo. Este nexo se conecta a su vez a la necesidad de reconocer la peculiar expresión semántica de esta copertenencia. La tesis que intentaría sostener aquí, a la sombra de Merleau-Ponty, es que esta copertenencia se sitúa en el plano de lo visible ${ }^{13}$ y aflora en el plano de la imagen. Esta última es una suerte de punto intermedio entre sujeto y objeto, está "más allá" de cualquier agotada alternativa entre uno y otro polo. Sobre esta base se ha intentado además llevar a cabo un arriesgado paso ulterior. Con estos presupuestos -valga lo dicho en el momento mismo del paso- se podría pensar que las formas vivientes constituyen, al transferirse en imagen, un modelo de ecosistema. Lo cual significaría que un ecosistema viviente se realiza no sólo, siempre y únicamente, desde el punto de vista cultural sino también, y más específicamente, con las facciones o rasgos de la imagen. La "naturaleza humana" está destinada, desde esta perspectiva, a autorrepresentarse. La naturaleza es el término último de cada agnición, una suerte de tierra prometida que estamos destinados a habitar. Esto explica, además, por qué no hay publicidad, desde Il Mulino bianco a Alpi Tours, que no recurra a imágenes de una naturaleza edénica o intacta entendida como lugar de deseo, como espacio ideal en el que asentarse. Todo esto -continuando con el atrevimiento...- parecería estar dando la razón a la propuesta de Edgar Morin según la cual el hombre es el único ser que se crea su propio ecosistema ${ }^{14}$. Y nos consentiría desarrollarla en dirección a una ontología de la imagen.

Una aproximación objetivante a estos temas pondría en cuestión este aspecto precisamente, el de la pertenencia recíproca de las formas vivientes en el ámbito del ecosistema.

12 Retomamos la expresión de G. Boehm que remite a Merleau-Ponty. Cfr. Boehm, G., "Die Wiederkehr del Blicke", en Was ist in Bild?, München, Fink, 1994, p. 21.

13 Cfr. M- Merleau-Ponty, L'occhio e lo spirito, Milano, SF, 1989. Id., Il visibile e l'invisibile, a cargo de M. Carbone, Milano, Bompiani, 2007.

14 Cfr. Morin, E., Il método, vol. 3, La conoscenza della conoscenza, trad. it. de A. Serra, Milano, Cortina, 2007; Id., Il método, vol. IV, Le idee: hábitat, vita, organizzazione, usi e costumi, Milano, Cortina, 2008. 
Lo que se configura así es la zona de una pertenencia simbólica (el ecosistema podría configurarse desde esta perspectiva como una retranscripción "laica" puesta al día de la simbología naturalista de los románticos) que despeja el camino a una nueva racionalidad depuesta y comprendida a la vez en la Anschaunng. Una intuición que tiene ahora la ocasión de desarrollarse sobre el terreno "sabio" de la imagen. Se lo puede definir como sabio en cuanto que articula extensivamente, vuelve perspicuo e inteligible cuanto se encuentra únicamente implícito en la Anschauung.

Estamos, así, en el ámbito de un proceso de transformación del saber que se realiza justamente dejando que vuelva a aflorar y suministrando un adecuado desarrollo a esa intuición que despunta. Nos las vemos, pues, en sustancia con una articulación de lo visible que corre paralela (no sin recíprocas contaminaciones) a la del concepto. Si quisiéramos hablar ahora -como ha sido hecho con frecuencia a partir de W.T.J. Mitchell15 - de un "pictorial turn" de la cultura tardo-moderna deberíamos hacerlo exactamente en este sentido, a saber, en cuanto hemos sido reconducidos a un terreno de fondo que, con todo, no es un terreno último. Se trata justamente de la lógica de una pertenencia compleja al fondo o marco de la lógica sumergida de la Anschauung, de la intuición, cuya simplicidad y cuyo estatuto fáctico -vale la pena destacarlo- deja por fin ahora aflorar lo que podría definirse como su estructura profunda. Cuanto emerge así y a la vez ante nuestros ojos es también y en consecuencia una simplificación o incluso algo más, una remoción de sus posibilidades cognitivas originarias y autónomas que habían sido petrificadas, por decirlo de algún modo, considerando a la intuición como si de un "dato" sensible se tratase.

A través de este reconocimiento de la profundidad de la Anschauung emerge una lógica de la estructura de la imagen que parece colindar con la lógica discursiva como poco. Se trata de una lógica de la forma. Y aquí el concepto de forma ha de entenderse como una estructura de la copertenencia de yo y naturaleza, de sujeto y objeto. ¿Qué otra cosa sino una estructura de la copertenencia de este tipo entendemos como mundo, es decir, como sistema completo de significados, como horizonte concluso a partir del cual es posible contemplar con aprensión o confianza las propias estrellas fijas?

La integración de la que se hablaba crea una estructura con una elevadísima tasa de complejidad. De hecho, gracias e esta integración -como se insinuaba más arriba- se estructura un mundo. Por otro lado, nuestra tarea se enfrenta a una configuración que permita reducir la complejidad inicial. En este caso entiendo la reducción de la complejidad según una acepción completamente personal. Coincide con la capacidad de transmitir un complejo muy articulado de informaciones en el tiempo más breve posible. Y el tiempo más breve posible en el que un sistema complejo puede transmitir el complejo de informaciones que él mismo representa es la

15 Cfr. Mitchell, W.T.J., Picture Theory, Chicago, The University of Chicago Press, 1994, pp. 11-34. 
simultaneidad. Nos enfrentamos aquí, por tanto, a una lógica de naturaleza particular. Se trata, en otros términos, de una lógica que articula y transmite los significados de la forma-imagen como resultado significativo de la /las copertenencia/as de sujeto y objeto. La podríamos definir -de manera provisional- como una morfológica no sólo y en tanto que lógica de la forma sino más bien en cuanto que formalógica, una forma que expresa una propia y peculiar sintaxis.

\section{Morfo-lógica. Más allá de la estetización de la imagen}

Se trata, pues, por encima de todo -como se ha dicho- de una Morfo-lógica, de una lógica que articula la intuición, la Anschauung, y que la expresa como estructura compleja en la imagen. Por otra parte, es una Morfo-lógica en la medida que es una lógica de la pertenencia a esa intuición que ha sido reconocida por fin según el estatuto que le compete, como "derivado" de la imagen y en ningún caso como dato originario.

Se puede expresar una tesis de esta naturaleza: la intuición, la Anschauung tiene la imagen como modalidad comunicativa propia, produce la propia estructura profunda, el propio logos en la imagen. Desde este punto de vista se trata de una estructura profunda que puede diferenciarse n-veces, tantas cuantas son las imágenes que "actúan" su umbral comunicativo.

$\mathrm{Si}$-como ocurre en este caso- se habla de umbral comunicativo y de su puesta en acto, se admite más o menos implícitamente que áquel es también un umbral interpretativo. ¿A qué pertenece en este caso la responsabilidad de la interpretación? Paradójicamente, también al objeto interpretado en cuanto constituye una estructura expresiva, una estructura que expresa un sistema de significados a través de su propia articulación en imagen. Desde este punto de vista entramos en contacto con una lógica que pone en cuestión al intérprete y a la interpretación allí donde el umbral comunicativo del que se hablaba no es de ninguna manera algo unívocamente determinado desde el principio, sino que es un umbral interpretativo, es decir, susceptible de interpretaciones diversas.

Si se concede crédito a la tesis que se ha desarrollado hasta este punto, deviene evidente hasta qué punto la idea de una cualificación preferentemente "estética" del universo de la imagen resulta a fin de cuentas desencaminada. Por "cualificación estética" de la imagen se entiende aquí algo próximo a la idea según la cual la imagen desagua por completo en los territorios de la apariencia allí donde tales territorios han sido asignados al arte y a sus instituciones, entre las cuales se indica en primer lugar el museo ${ }^{16}$. La imagen, homologada con el arte, resulta, en este cuadro,

\footnotetext{
16 Véase en este sentido Belting, H., Bild und Kult. Eine Geschichte des Bildes vor dem Zeitalter der Kunst, München, Beck, 1990; Id., Das Ende der Kunstgeschichte. Eine revision nach zehn Jahren,
} 
relegada a los territorios de la apariencia y de la ilusión en el marco de una sucesión de acontecimientos que nos llevan hasta el décimo libro de la República platónica nada menos. Se supone que, en este ámbito estético, la imagen no tiene eficacia alguna fuera de los confines que se le atribuyen. Quizás son ya suficientes estas muy superficiales observaciones para captar la dimensión de un problema que repropone de manera alto evidente la cuestión del destino de todo el universo restante de la imagen. La cuestión que, para entendernos, no puede quedar connotada principalmente como estética. Ronda por aquí en sentido amplio -por decirlo no sin cierta ironía- la marxiana "crítica de la ideología". ¿A dónde ha ido a parar la potencia de la imagen? ¿En qué zahúrdas ha quedado encerrada? Esta es la pregunta que ahora se propone. ¿Dónde y cuándo se ha disuelto aquella potencia que el mito era capaz de expresar con extraordinaria eficacia haciendo de la propia narración un verdadero y auténtico acontecimiento? Tráigase a la memoria el relato de Hesiodo sobre Afrodita, que nace fúlgida de las aguas, poniendo fin a un atormentado conflicto, haciéndose de esta manera y al mismo tiempo testimonio del surgir de un mundo atrayente y ordenado a partir de un enfrentamiento lacerante y caótico. Estamos ante una potencia que hoy parece extenderse de una manera más o menos oculta -limitándose a una breve señal sobre un camino que de lo contrario nos conduciría demasiado lejos- a las más diversas formas de persuasión social, desde la publicidad a la política17. También esto resulta probablemente una consecuencia de la estetización de la imagen, la cual -como se decía más arriba- ha vaciado la imagen mítica de su originaria potencia y ha vuelto disponible su potencial para otros usos bien distintos. La imagen estética depotenciada desarrolla por su parte ese estéril atractivo que se concreta en la fórmula kantiana del "placer sin interés".

Esta imagen estetizada constituye el pendant ideal de la imagen objetivada bajo formas de la intuición. De la misma manera que la intuición depotencia de hecho la imagen objetivándola, así también la conciencia estética la substrae al propio tejido viviente, la aísla haciendo de ella una especie de cosmos separado, privado de influencia fuera de sus propios límites ${ }^{18}$.

¿Cuándo nace, pues, la intuición, la Anschauung? Intentemos una primera respuesta hipotética. Nace cuando la imagen pierde su potencial mágico, que estaba unido a su rostro estético y a aquello que en sentido amplio se podría llamar espistémico ${ }^{19}$. La Anschauung es la anestetización de la imagen para que resulte apro-

München, segunda edición ampliada, 2002; Nehamas, A., Only a Promise of Happiness. The Place of Beauty in a World of Art, Princenton, Princenton University Press, 2007.

17 Me permito aludir en este sentido y, hablando en general, por lo que se refiere a esta consideraciones sobre la "potencia" de la palabra mítica a la Introducción de mi obra Oltre la belleza, Bologna, Il mulino, 2008.

18 Véase a este propósito naturalmente los fundamentales análisis de Gadamer, H.G., Verità e método, a cargo de G. Vattimo, Milano, Bompiani, 2000, primera parte.

19 Cfr. Blumenberg, H. Arbeit am Mythos, Frankfurt a. M., Suhrkamp, 1979. 
piada para fines cognoscitivos. Ella deviene antes que nada repertorio de la reflexión epistemológica, que la codifica como percepción en su modalidad de dato objetivo. Por su parte, el surgir de la estética parece exorcizar el riesgo que se cierne sobre ella con el despertar de la imagen dormida bajo los rasgos de la intuición: la estética se retrae atemorizada ante una imagen que se asoma de nuevo al balcón y hace de la intuición no un "derivado" de la imagen por encima de todo sino un momento secundario con respecto al concepto. Para completar el proceso de anestetización de la imagen bajo los ropajes de la intuición interviene por fin la transformación de la estética en "filosofía del arte". Lo que comporta -como queda ejemplarmente testimoniado por Hegel, que es al artífice mayor de esta transformación-que la imagen se estetice al completo y se presente envuelta en los ropajes de la apariencia estética, privada ya definitivamente de cualquier influencia sobre el mundo 20 . La belleza es ahora para Hegel sólo la "belleza artística [...] la belleza generada y regenerada por el espiritu", cuyo destino es la moderna conciencia estética ${ }^{21}$, mientras lo bello natural se vuelve irrelevante y la naturaleza queda privada de toda significación autónoma.

Hay que entender el iconic turn en el contexto que hemos delimitado brevemente, a saber, en el sentido de una renovada conciencia de la naturaleza "potente" de la imagen que vuelve a proponer el cruce entre la significación natural y la significación cultural. En la medida que restablece la antigua potencia ínsita en el propio conocer, una potencia de origen mítico que reenvía a la posibilidad de dominar la naturaleza externa, hasta la propia imagen tecnificada deja adivinar un rostro arcaico de acuerdo con una intuición que fue ya la de Adorno y Horkheimer en la Dialéctica de la Ilustración.

\section{Apariciones}

Desde este punto de vista y en este cuadro deviene incluso posible definir la estructura conjunta objetiva y subjetiva de la imagen. La categoría de lo sublime vuelve a ser útil en este cuadro. Se nos vuelve útil cuando queremos proponer la cuestión de su peculiar articulación semántica. Se trata de una primera célula de la cuestión que hemos propuesto llamar morfo-lógica. Como ya se ha insinuado, la imagen posee una articulación semántica sustancialmente consagrada a un mínimo derroche de energía. Una articulación muy atenta a la economía energética de la comunicación, que transmite un contenido complejo en el tiempo más breve posible, a saber, simultáneamente. La economía del mínimo esfuerzo se impone en el

20 Véase en relación con esto y concretamente en relación con el concepto de belleza Nehamas 2007 op. cit., (nota 16); Id. Bild-Anthropologie. Entwürfe für eine Bildwissenschaft, München, Beck, 2001. ${ }^{21}$ Hegel, G.W.F., Estetica, a cura di N. Merker, Torino, Einaudi, 1997, p. 6. 
cuadro de un progresivo aumento de la complejidad y sobre la base de la necesidad de superarla sin traicionarla, teniendo fe en la exigencia -ínsita en la lógica de la imagen- de transmitir un sistema complejo en un tiempo decisivamente más breve de aquél que consiente la lógica discursivo/conceptual fundada sobre la estructura sujeto/cópula/predicado.

Una vez admitido que la imagen como tal es un sistema complejo, se impone preguntarse cómo es posible que las propias imágenes se articulen las unas con las otras según una modalidad alternativa de aquella que provee la articulación discursiva. ¿Cómo puede producirse la conexión de las imágenes? ¿De qué manera pueden ponerse en relación suministrando alguna forma de secuencia organizada que sea en sentido amplio "lógica"? Oriento aquí el discurso al intento de echar una primera, inicial ojeada sobre la cuestión.

Como primera ocurrencia se podría decir que la condición para que se dé la conexión de imágenes es también aquélla que hace posible su manifestación, aquélla que consiente su aparecer. A este propósito, es el momento de recoger una enseñanza romántica que proviene de Philipp Otto Runge. Para poder aparecer, para asumir la configuración que les compete, las imágenes necesitan de un fondo oscuro que las deje emerger. Esto es cuanto testimonian las páginas de Runge, que se identifican -de una manera que no podría darse en la naturaleza- gracias a este fondo que pone en evidencia su contorno o perfil. Tal vez se pueda decir incluso algo más, cuando pensamos en el influjo que Runge recibe de Jakob Böhme. Se podría leer la proveniencia de la imagen a partir del fondo, su emergencia a partir del tejido de lo creado. Acogiendo esta interpretación -en lo que respecta a Runge por lo menos- se puede decir que la nada, en cuanto fondo, es la condición de ser de la emergencia de la imagen.

Se podría desarrollar una tesis de este tipo prescindiendo del contexto romántico de su primera formulación. Se podría afirmar -extrapolando justamente esta idea de su lugar originario- que, para poder manifestarse en su completud morfológica (y no quedar reducidas a signos, casi a puntos sin extensión), las imágenes se dirigen siempre más allá de sí, más allá de su propio perímetro y de sus propios confines. El fondo es en efecto su condición de ser, como se decía a propósito de Runge. Para hacer emerger el propio ser y con ello su identidad, su significado, las imágenes deben asomarse a aquella nada de la que provienen. Para desautorizar la amenaza de la nada y a la vez sacar provecho de ella -los dos opuestos caminan aquí juntos-, las imágenes intentan unirse a otras imágenes sin conocer a priori la fórmula que les permitiría alcanzar su objetivo. Así pues, ellas están abocadas siempre al abismo. Y justo de esta manera instituyen las imágenes su peculiar sintaxis. Se trata de una articulación que no se funda sobre la evidencia de la cópula sino sobre el intento de exorcizar la nada. Y la nada no es sólo la condición del aparecer de la imagen tout court sino también -como se ha dicho más arriba- de su aparecer como imagen. 
Podríamos afirmar por tanto que, al contrario del discurso, la imagen se vuelve reconocible porque -al menos en primera instancia- se propone esencialmente en su singularidad al abrigo de un fondo que la pone en riesgo pero la vuelve intuible al mismo tiempo. De esta manera, la imagen se da a entender a través de su intrínseca semántica, a partir de su peculiar sintaxis. Por así decir, se ve obligada a mirar a través de sí misma más allá de sí misma. Ella puede establecer sobre esta base -prescindiendo de su conexión con el resto del universo de la imagen y con otros universos semánticos- su propia relación mínima: la referencia. Es imagen de... Y esto confirma que la trascendencia constitutiva de la imagen es también la condición que la hace reconocible y por tanto de aquello que podría definirse como su estatuto ontológico.

En resumen: las imágenes son imágenes, a saber, manifestaciones de todo aquello que a través de ellas emerge en la medida que puede recurrir al "fondo de nada" que exhibe su adecuada evidencia. Gracias a este fondo se manifiesta la diferencia ontológica que las define consustancialmente como imágenes, que hace en otras palabras que la imagen sea "imagen de...".

Ahora bien, si el hacerse imagen de una estructura sígnica depende de su abismarse en la nada -he aquí que nos enfrentamos ipso facto con la estructura de lo sublime. La verdad de una afirmación como ésta se deduce también e contrario: los signos que organizan el discurso verbal manifiestan ante todo su cualidad sígnica y no "imaginaria" en la medida que, por encima de todo, son situados y vistos en secuencia. Pero esto no vale para la imagen, que manifiesta "potentemente" su significado incluso en solitario. Ella "busca" lo coral pero no lo posee desde el principio. En otros términos, algo llega a significar "en imagen" en tanto en cuanto transforma en lo infinito, en la $n$ que indica una plurivocidad de reenvíos indefinida por principio, esa ojeada a la nada que podría aniquilarla. En este proceso la imagen deviene imagen, es decir, se estructura semánticamente de acuerdo con su peculiar articulación. Desde este punto de vista, la imagen es el sujeto y el objeto del propio estructurarse allí donde, en el límite, la misma distinción de esos dos planos adquiere un significado casi nulo: pues no se ve desde qué punto de vista se pueda estructurar la mirada desde lo alto o de frente que suministra a la estructura sujeto-objeto su movimiento peculiar. Estamos, en efecto, más allá de la muerte de Dios. 